\title{
The influence of temperature and light on parthenocarpy in pickling cucumbers (Cucumis sativus L.)
}

\author{
O. M. B. de Ponti
}

Institute for Horticultural Plant Breeding (IVT), Wageningen, the Netherlands

Key words: Cucumis sativus, pickling cucumber, parthenocarpy, temperature, light

\section{Summary}

Parthenocarpy in pickling cucumbers is influenced unfavourably by high temperatures. The effect of high day temperatures can partly be compensated by low night temperatures. A temperature regime of $23 / 17^{\circ} \mathrm{C}$ seems to be optimal. The influence of daylength and lightintensity is discussed.

\section{Introduction}

The few reports on the influence of temperature on parthenocarpy in Cucumis sativus L. (Nitsch, 1952; Nitsch et al., 1952; Borghi, 1970; Rudich et al., 1977; Kubicki, pers. comm.) and in Cucumis pepo L. (Rylski, 1974) are unanimous in their conclusion that lower temperatures stimulate parthenocarpy.

Because in the Netherlands pickling cucumbers are grown in the open as well as in glasshouses, it still appeared necessary to examine how the newly bred parthenocarpic lines (de Ponti, 1976; de Ponti \& Garretsen, 1976) react to different temperatures. By carrying out experiments in different seasons some information on the influence of light has also been gained.

\section{Materials and methods}

Three experiments were carried out in temperature-controlled, insect-proof glasshouses of the phytotron of our institute. In the first experiment four highly parthenocarpic gynoecious lines were placed at constant temperatures of 17, 20 and $23{ }^{\circ} \mathrm{C}$, when the first female flower-bud was visible. Per line 7 plants were used per temperature. They were pruned by removing the laterals after the first node. On the main stem up to the 20th node and on the first node of the laterals the number of parthenocarpic fruits and aborted ovaries was recorded. Then the parthenocarpy percentage was calculated as follows:

$\%$ parthenocarpy $=\frac{\text { number of parthenocarpic fruits }}{\text { total number of female flowers }} \times 100$.

These observations were made from 15 August to 15 October 1973. In this period 
the average radiation in the open varied from 6000 to $17000 \mathrm{~J} / \mathrm{cm}^{2}$ per ten days and the daylength decreased from 14.5 to 10.5 hours.

In the second experiment the above four lines were investigated at different day ( 8 hours) and night $\left(16\right.$ hours) temperatures $\left(26 / 20,26 / 17,23 / 20,23 / 17^{\circ} \mathrm{C}\right.$ ) and at $20^{\circ} \mathrm{C}$ constant. The experimental design and the observations were as above except that the records were restricted to only the main stem up ot the 12th node. The experiment lasted from 1 to 31 August 1974, during which period the average radiation in the open varied from 14000 to $17500 \mathrm{~J} / \mathrm{cm}^{2}$ per ten days and the daylength decreased from 15.5 to 13.5 hours.

The third experiment ran from 1 February to 15 March 1975, when the average radiation in the open varied from 5000 to $9500 \mathrm{~J} / \mathrm{cm}^{2}$ per ten days and the daylength increased from 9 to 12 hours. Per line 10 plants were placed at 26, 26/20, $26 / 17,23,23 / 20,23 / 17$ and $20^{\circ} \mathrm{C}$. Due to lack of seeds of the four lines used in experiments 1 and 2 three related lines were used. The experimental design and the observations were the same as in the second experiment.

The data on radiation were obtained from the Department of Physics and Metereology of the Agricultural University of Wageningen.

\section{Results and discussion}

Because there was no interaction between lines and temperatures, the data of the individual lines have been taken together. The results of the three experiments, summarized in Table 1, show that parthenocarpy is promoted by relatively low temperatures. Judging by the results of the first experiment one might consider $20^{\circ} \mathrm{C}$ as the optimum temperature for growing parthenocarpic pickling cucumber varieties. At this temperature the high parthenocarpy percentage is associated with a rather rapid vegetative and generative development resulting in an early and high yield of parthenocarpic fruits. The absence of day/night fluctuations, however, is very unnatural.

In the second experiment, therefore, the effect of lower night temperatures was studied, especially in combination with unfavourably high day temperatures. It appears that decreased night temperatures can, at least partly, compensate the negative effect of relatively high day temperatures. Although the parthenocarpy percentage was significantly higher at $20^{\circ} \mathrm{C}$ than at $23 / 17^{\circ} \mathrm{C}$, the latter temperature regime seems to be preferable, because it gives a higher yield of parthenocarpic fruits as a result of its positive influence on flower initiation.

The third experiment has been carried out under extremely poor light conditions in a season when pickling cucumbers are not commercially grown. It is evident that the general level of parthenocarpy under these conditions is very low.

Again a stimulative effect of low temperatures can be noticed, if constant temperatures are compared, but there is no compensative effect of decreased night temperatures.

From this experiment it is difficult to decide if the negative influence of the poor light conditions on parthenocarpy is due to the shorter day, to the low light intensity or to both. A daylength effect has also been observed in earlier experiments (Kvas- 
O. M. B. DE PONTI

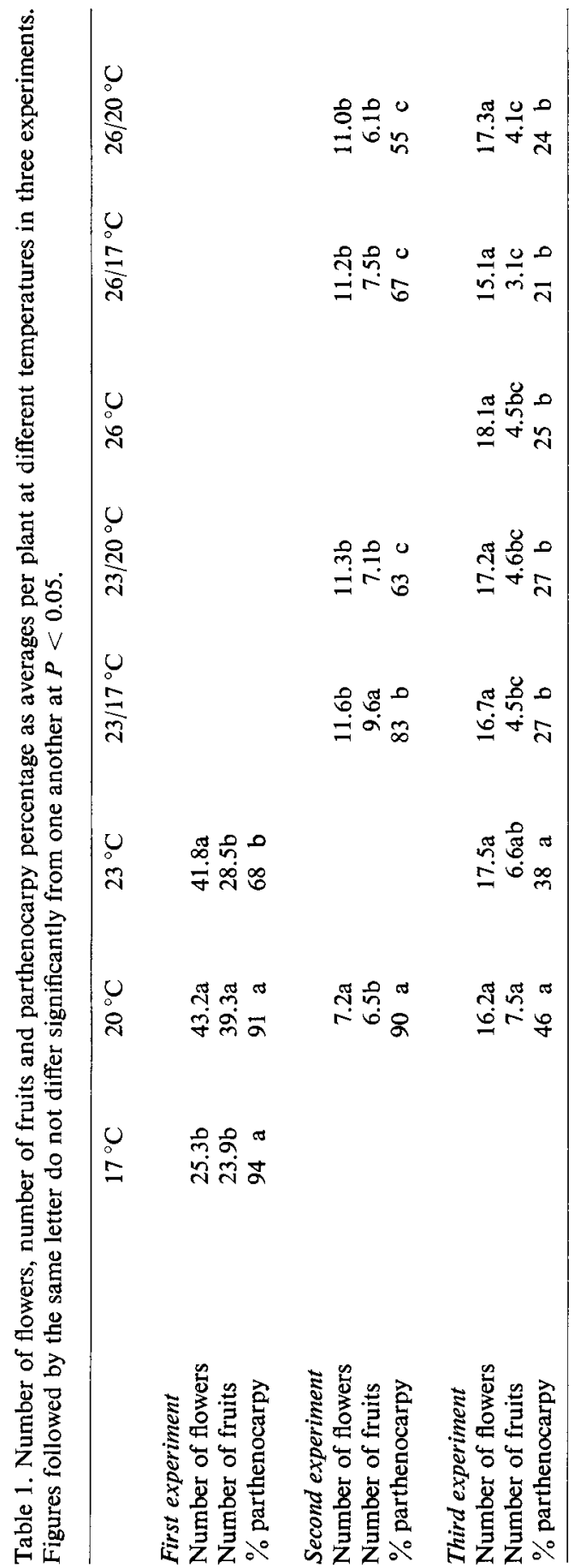


nikov et al., 1970; Rylski, 1974; de Ponti, 1976). However, it seems unlikely that this effect alone is responsible for the sharp decrease observed. A stimulative effect of high light intensities has been reported by Nitsch (1952). Further research might clarify the real significance of both light factors.

Although this research was rather limited and only involved parthenocarpic lines of one genetic origin, one might wonder if it does not indicate that growing parthenocarpic pickling cucumber varieties outside the temperate climatic regions will be hampered by a negative influence of high temperature. It is but speculative to suppose that the positive influence of higher light intensities (Nitsch, 1952) in warmer regions would (partly) compensate this effect.

\section{Acknowledgment}

Thanks are due to Miss Izabela Zuradzka and Mr J. M. Alvarez, who made most of the observations.

\section{References}

Gorghi, B., 1970. La partenocarpia nel cetriolo, Cucumis sativus L. Riv. Ortofl. Ital. 54: 318-327.

Kvasnikov, B. V., N. T. Rogova, S. I. Tarakanova \& S. I. Ignatova, 1970. Methods of breeding vegetable crops under the covered ground. (Russian, English summary.) Trudy prikl. Bot. Genet. Selek. 42(3): 45-57.

Nitsch, J. P., 1952. Plant hormones in the development of fruits. $Q$. Rev. Biol. 27: 33-57.

Nitsch, J. P., E. Kurtz, Jr., J. Livermann \& F. Went, 1952. The development of sex expression in cucurbit flowers. Am. J. Bot. 39: 32-43.

Ponti, O. M. B. de, 1976. Breeding parthenocarpic pickling cucumbers (Cucumis sativus L.): necessity, genetical possibilities, environmental influences and selection criteria. Euphytica 25: 29-40.

Ponti, O. M. B. de \& F. Garretsen, 1976. Inheritance of parthenocarpy in pickling cucumbers (Cucumis sativis L.) and linkage with other characters. Euphytica 25: 633-643.

Rudich, J., L. R. Baker \& H. M. Sell, 1977. Parthenocarpy in Cucumis sativis L. as affected by genetic parthenocarpy, thermo-photoperiod, and femaleness. J. Am. Soc. hort. Sci. 102: 225-228.

Rylski, I., 1974. Effects of season on parthenocarpic and fertilized summer squash (Cucumis pepo L.). Expl Agric. 10: 39-44. 